\title{
ThinPrep ve Konvansiyonel Yöntem ile Çalışılan Servikal Smear Sonuçların Değerlendirilmesi
}

\author{
The Evaluation of Cervical Smear Results Assessed by ThinPrep and Conventional Methods
}

\author{
Resul ARISOY ${ }^{1}$, Cihangir YILANLIOĞLU ${ }^{1}$, Koray ÖZBAY ${ }^{1}$, Altuğ SEMİZ ${ }^{1}$, Alparslan DENİZ ${ }^{1}$ \\ 1. Şişli Memorial Hastanesi, Kadın Hastalıkları ve Doğum Kliniği, İstanbul, Türkiye
}

\begin{abstract}
ÖZET
Amaç: Hastanemizde yapılmış olan servikal smear sonuçlarının yıllara ve hasta yaşına göre değerlendirilmesi, anormal sonuç oranlarının ve dă̆llımının araştırılması, kullanılan inceleme yöntemine göre sonuç dağılımında farklılık olup olmadığının belirlenmesi ve sonuçların ülkemiz epidemiyolojik verilerine katkıda bulunmasidır.
\end{abstract}

Gereçler ve Yöntem: 2010 Haziran-2014 Aralı tarihleri arasında Şişli Memorial Hastanesi jinekoloji polikliniğine başvuran ve servikal smear testi yapılan hastaların sonuçlarını retrospektif olarak analiz ettik. Çalışmamıza 21-65 yaş arası 32.617 hasta dahil edildi.

Bulgular: Olguların dă̆llımı incelendiğinde $29.831(\% 91,5)$ olgunun patoloji sonucu normal, 1.713 olguda $(\% 5,25)$ ASCUS, 135 olguda $(\% 0,4) A S C-H, 21$ olguda $(\% 0,06) A G C$, 767 olguda $(\% 2,35)$ LSIL, 131 olguda $(\% 0,4)$ HSIL, üç olguda adeno kanser ve iki olguda da skuamöz kanser tespit edilmiştir. Tüm olgular değerlendirildiğinde anormal sonuç ora-

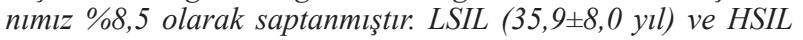
$(34,4 \pm 7,2$ yıl) olgularının anlamlı olarak daha genç yaşlarda olduğu saptandl.

Sonuç: Çalışmamızda, ThinPrep yöntemi ile yıllar bazında prekanseröz lezyon saptanma oranlarında bir artış saptadık.

Anahtar Kelimeler: bethesda sistemi, konvansiyonel yöntem, thinprep yöntemi, servikal smear

\section{ABSTRACT \\ Objective: Our aim was to evaluate cervical smear results ac- cording to years and patient age. We investigated the abnormal outcome rates and distribution to determine whether there is any difference in smear results according to the examination method used and to contribute to the epidemiological data of our country.}

Material and Methods: We retrospectively analyzed the cervical smear test results of the patients who were admitted to gynecology outpatient clinic of Şişli Memorial Hospital between June 2010 and December 2014. 32.617 patients aged 21-65 years were included in our study.

Results: The pathology result was determined to be normal in 29.831 patients (91.5\%). ASCUS, ASC-H and AGC were detected in $1.713(5.25 \%), 135$ (0.4\%) and 21 (0.06\%) patients respectively. LSIL was detected in 767 cases (2.35\%), HSIL in

\section{İletișim}

Sorumlu Yazar: Resul ARISOY

Adres: Şişli Memorial Hastanesi, Kadın Hastalıkları ve Doğum Kliniği, İstanbul, Türkiye

Tel: +90 (212) 3146666

E-Posta: drresular@hotmail.com

Makale Geliș: 21.04.2019

Makale Kabul: 19.05.2019

DOI: http://dx.doi.org/10.16948/zktipb.556517
131 cases (0.4\%), adeno cancer in three cases and squamous cancer in two cases. When all the cases were evaluated, the rate of abnormal results was found to be $8.5 \%$. LSIL (35.9 \pm 8.0 years) and HSIL (34.4 \pm 7.2 years) were detected at significantly younger ages.

Conclusion: In our study, we detected an increase in the prevalence of precancerous lesions in years by ThinPrep method.

Keywords: bethesda system, conventional method, thinprep method, cervical smear

\section{GíRiș}

Serviks kanseri 2018 yılı verilerine göre tahminen 570.000 yeni vaka ile bütün kadın kanserlerinin \%6,6'sından sorumlu ve kadınlarda en s1k görülen dördüncü kanser türüdür. Büyük oranda HPV enfeksiyonuna sekonder gelişmektedir. Servikal kanser nedeni ile oluşan ölümlerin yaklaş1k \%90'1 düşük ve orta gelir seviyeli ülkelerde gerçekleşmiştir (1). Yüksek mortalite oranlarına sahip serviks kanseri, etkili tarama programları sayesinde prekanseröz lezyonların erken teşhis ve tedavisi sağlanarak engellenebilmektedir. Prekanseröz lezyonların belirlenmesi ve tedavileri sağlanarak kanser oluşumunun önlenmesi amacıyla protokoller geliştirilmektedir. Organize servikal tarama programlarının servikal kanser mortalitesini \%80'e kadar düşürebildiği gösterilmiştir $(2,3)$.

Prekanseröz lezyonların etkin teşhisi amacıyla son dönemde bir çok yeni teknik üzerine çalıșmalar yapılmaktadır. HPV DNA taraması, FISH ve/veya diğer in situ hibridizasyon uygulamaları, dijital servikografi gibi birçok yeni teknik geleceğe dair umut vadetmekle beraber günümüzde servikal sitolojik tarama halen yaygın bir metottur (4-7). Ülkemizde yapılan bir çalışmada bir milyon HPV DNA testi değerlendirilmiş ve konvansiyonel Pap smear'e göre daha efektif olduğu ve birinci basamak taramada kullanılabileceği belirtilmiştir (8).

Servikal sitoloji taramasinda günümüzde yaygin olarak 2001 The Bethesda System (TBS) kullanılmaktadır. Pap smear test rutin tarama yöntemi olarak kabul edilmektedir. TBS kullanılarak prekanseröz lezyonların saptanması kanserlerin erken teşhis, tedavi ve önlenmesini sağlamaktadir. TBS 2014'te revize edilmiș ve terminolojide minimal değişiklikler yapılarak, sitolog ve klinisyenlere temel konseptler için daha çok kaynak, daha çok morfolojik ipuçları, histolojik korelas- 
yon bilgisi sağlanması amaçlanmış ve durumun yönetimi için kılavuzda güncellemeler yapılmıştır $(3,7,9,10)$. Biz çalışmamızda polikliniğimize başvuran hastaların rutin jinekolojik kontrolleri sırasında alınan Pap smear sonuçlarını retrospektif olarak değerlendirmeyi amaçladık.

\section{GEREÇ ve YÖNTEM}

2010 Haziran-2014 Aralık tarihleri arasında Şişli Memorial Hastanesi jinekoloji polikliniğine başvuran ve servikal smear testi yapılan hastaların sonuçlarını retrospektif olarak analiz ettik.

Smear alınan kişiler, 21 yaşından büyük ve seksüel olarak aktif yaşam öyküsü olan hastalardı. Genel olarak polikliniklere başvuran hastalardan anamnezden sonra, servikal Pap smear hakkında bilgi verilip bu testi kabul edenlerden öncelikle spekulum yerleştirilip örnek materyal alınmaktadır. Muayene esnasinda kanaması, yoğun vajiniti, vajinal ilaç kullanımı, ilişki sonrası ya da duş hikayesi olanlardan örnek alınmamıştır. İşlem sonrası bimanuel muayeneleri ve ultrasonografik değerlendirmeleri yapılmıştır. Ayrıca 65 yaş üstü smear sonuçları çalışma dışı bırakılmıştır.

Servikal sitoloji örneği, smear firçası eksternal servikal os'a yerleştirilerek ve saat yönünde $360^{\circ}$ çevrilerek alındı. Bir kısım hastada konvansiyonel teknikle, toplanan hücresel materyaller lam üzerine yayılarak fikse edilmiş ve kapalı kutularda patoloji bölümüne ulaştırılmıştır. Diğer bir grup hastada likit bazlı sitoloji yöntemi kullanılmış, smear firçası koruyucu solüsyon (PreserveCyt Solution 20 ml, Hologic Inc., Marlborough, USA) bulunan bir kaba aktarılmıss ve "ThinPrep Pap Test and Imaging System" (TPITS, Hologic Inc., Bedford, MA, USA) ile değerlendirilmek üzere kapalı bir şekilde patoloji bölümüne ulaştırılmıştır. Smear sonuçları 2001
TBS'e göre değerlendirilmiștir.

Hastaların tanımlayıcı özellikleri (protokol, yaş, tarih) ve smear sonuçları hastanemizin patoloji değerlendirmelerini yapan Nişantaşı Patoloji Grubu laboratuarları datasından elde edilmiștir.

İstatistiksel analizler için SPSS 11.5 paket programı (SPSS Inc., Chicago, IL, ABD) kullanıldı. Tanımlayicı istatistiksel (ortalama, standart sapma, yüzde) analizler yapıldı. One way ANOVA test ve Ki-kare test yapıldı. Sonuçlar $\% 95$ güven aralığında değerlendirildi ve $p<0,05$ istatistiksel olarak anlam11 kabul edildi.

\section{BULGULAR}

Çalışmamıza 32.617 hasta dahil edildi. Çalışmamizda 7.240 olguda konvansiyonel smear tekniği ve 25.377 olguda da ThinPrep tekniği kullanılmıştır. Olguların dağılımı incelendiğinde 29.831 $(\% 91,5)$ patolojisi normal, 1.713 olguda $(\% 5,25)$ ASCUS, 135 olguda $(\% 0,4)$ ASC-H, 21 olguda $(\% 0,06)$ AGC, 767 olguda $(\% 2,35)$ LSIL, 131 olguda $(\% 0,4)$ HSIL ve 3 olguda adeno kanser iki olgudada skuamöz kanser tespit edilmiştir. Olguların dağılımı Tablo 1'de verilmiştir.

Çalışma grubunda ortalama yaş $37,8 \pm 8,5$ yıl, yaş aralığı 21-65 yıl olarak saptandı. Olguların sitolojik değerlendirme sonuçlarına göre yaş dağ 1 lımlar1 Tablo 2'de verildi. LSIL (35,9 $\pm 8,0$ yil) ve HSIL $(34,4 \pm 7,2$ yıl) olgularının anlamlı olarak daha genç yaşlarda olduğu saptand $1(\mathrm{p}<0,001)$.

Smear sonuçlarının yıllara göre dağılımı Tablo 3'te verildi. 2013-2014 yillarında patolojik smear sonuçlarında anlamlı bir artış tespit edildi. 2010 y1lında hastaların \%93,4'de smear sonuçları normal iken, 2011 y1lında \%94,3'ü, 2012 yılında \%92,8'i, 2013 yılında $\% 88,1$ 'i ve 2014 yilında da $\% 90,2$ 'si normal olarak tespit edildi.

Tablo 1: Olguların dağılımı.

\begin{tabular}{|c|c|c|c|c|c|c|c|c|c|c|c|}
\hline \multicolumn{2}{|l|}{ Smear Tekniği } & Normal & ASCUS & ASCH & AGC & LSIL & HSIL & İNVAZİV & $\begin{array}{l}\text { ASCUS } \\
\text { AGC }\end{array}$ & $\begin{array}{l}\text { ASCH } \\
\text { AGC }\end{array}$ & Toplam \\
\hline \multirow{2}{*}{$\begin{array}{l}\text { Konvansiyonel } \\
\text { Teknik }\end{array}$} & $\mathrm{N}$ & 6856 & 344 & 3 & 16 & 16 & 3 & 2 & 0 & 0 & 7240 \\
\hline & $\%$ & 94,7 & 4,75 & 0,04 & 0,2 & 0,2 & 0,04 & 0,02 & 0,0 & 0,0 & $\% 100,0$ \\
\hline \multirow{2}{*}{ ThinPrep } & $\mathrm{N}$ & 22975 & 1369 & 132 & 5 & 751 & 128 & 3 & 10 & 4 & 25377 \\
\hline & $\%$ & 90,5 & 5,4 & 0,5 & 0,01 & 3,0 & 0,5 & 0,01 & 0,03 & 0,01 & $\% 100,0$ \\
\hline \multirow{2}{*}{ Toplam } & $\mathrm{N}$ & 29831 & 1713 & 135 & 21 & 767 & 131 & 5 & 10 & 4 & 32617 \\
\hline & $\%$ & 91,5 & 5,25 & 0,4 & 0,06 & 2,35 & 0,4 & 0,01 & 0,03 & 0,01 & $\% 100,0$ \\
\hline
\end{tabular}

Tablo 2: Sitoloji sonuçlarına göre olguların yaş dağılımı.

\begin{tabular}{|c|c|c|c|c|c|c|c|c|}
\hline \multicolumn{9}{|c|}{ Hastaların Yaş Dağılımı (Yıl) } \\
\hline \multirow{2}{*}{ Sitoloji sonucu } & \multirow{2}{*}{$\begin{array}{c}\text { Olgu Sayısı } \\
\text { (n) }\end{array}$} & \multirow{2}{*}{$\begin{array}{c}\text { Ortalama } \\
\text { Yaş }\end{array}$} & \multirow{2}{*}{$\begin{array}{c}\text { Std. } \\
\text { Sapma }\end{array}$} & \multirow{2}{*}{$\begin{array}{l}\text { Std. } \\
\text { Hata }\end{array}$} & \multicolumn{2}{|c|}{ \%95 Güvenlik aralığı } & \multirow{2}{*}{ Minimum } & \multirow{2}{*}{ Maksimum } \\
\hline & & & & & Alt sinir & Üst sınır & & \\
\hline NORMAL & 29831 & 37,93 & 8,514 & ,049 & 37,83 & 38,03 & 21 & 65 \\
\hline ASCUS & 1713 & 36,77 & 8,098 & ,196 & 36,39 & 37,16 & 21 & 65 \\
\hline ASC-H & 135 & 36,08 & 7,672 & ,660 & 34,78 & 37,39 & 21 & 61 \\
\hline AGC & 21 & 38,90 & 9,685 & 2,113 & 34,50 & 43,31 & 23 & 54 \\
\hline LSIL & 767 & 35,87 & 8,044 & ,290 & 35,30 & 36,44 & 21 & 64 \\
\hline HSIL & 131 & 34,35 & 7,192 & ,628 & 33,11 & 35,59 & 21 & 65 \\
\hline İnvaziv Kanser & 5 & 33,80 & 2,588 & 1,158 & 30,59 & 37,01 & 30 & 37 \\
\hline ASCUS-AGC & 10 & 36,40 & 6,346 & 2,007 & 31,86 & 40,94 & 26 & 45 \\
\hline ASCH-AGC & 4 & 40,25 & 6,500 & 3,250 & 29,91 & 50,59 & 31 & 46 \\
\hline Toplam & 32617 & 37,80 & 8,486 & ,047 & 37,71 & 37,89 & 21 & 65 \\
\hline
\end{tabular}


Tablo 3: Sitoloji sonuçlarının yıllara göre dağılımı.

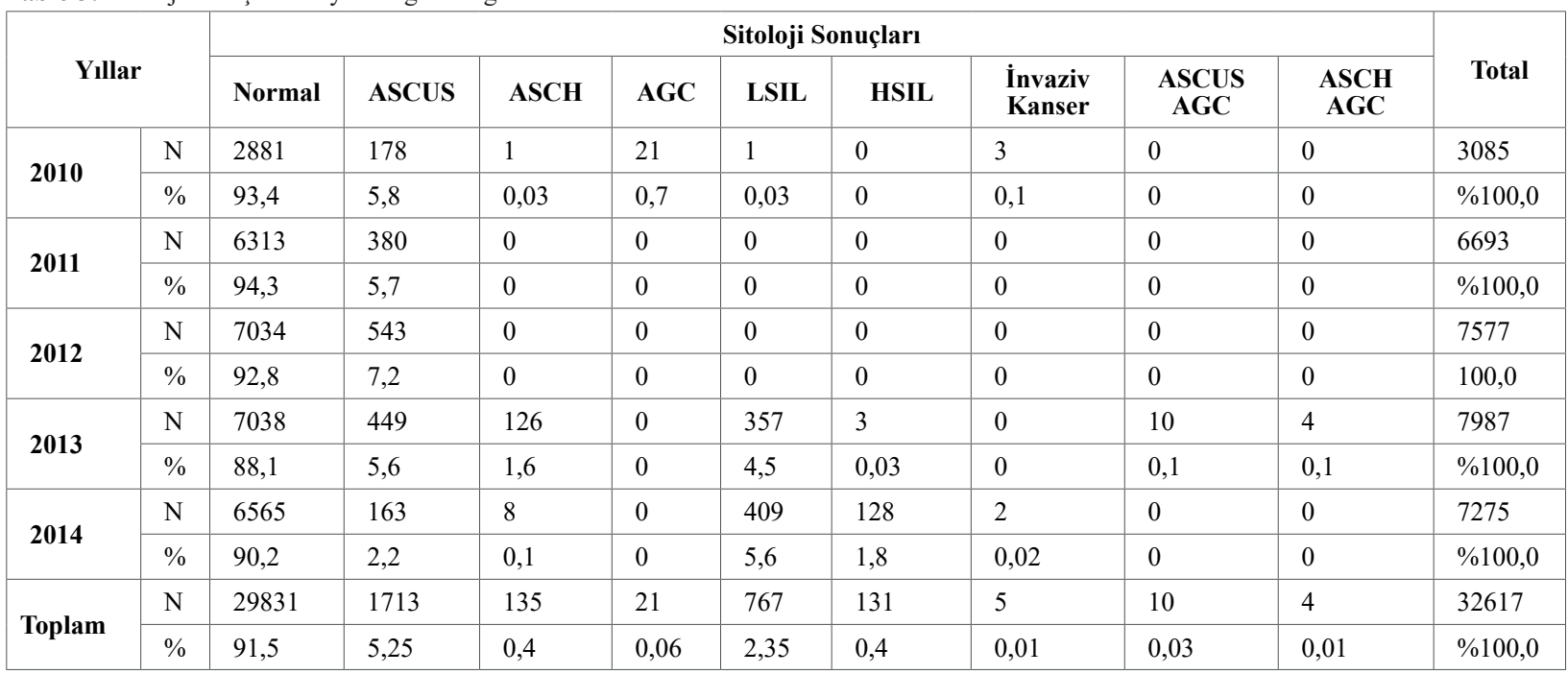

\section{TARTIŞMA}

Servikal prekanseröz lezyonlar non-invaziv yöntemler yardımıyla belirlenebilen ve yüksek başarı oranları ile tedavi edilebilen lezyonlardır. İnvaziv kanser safhası sonrası hızlı bir seyir ve yüksek mortalite oranlarına sahip bir kanser türü olan serviks kanseri, etkin tarama yöntemleri ile prekanseröz aşamada teşhis ve tedavi edilebilmesi sebebi ile servikal sitoloji tarama protokolleri olușturulmuştur. Teknolojik ilerleme ve yapılan çalışmalar neticesinde servikal taramada konvansiyonel Pap smear taramaları yerine yeni tarama yöntemleri denenmektedir. HPV DNA taramaları ve FISH veya diğer in situ hibridizasyon taramaları spesivitesi ve sensitivitesi yüksek olan yöntemler olarak rapor edilmiştir $(5,7)$.

Servikal sitolojilerde TBS'e göre prekanseröz lezyonların görülme sıklığı ülkeler arasında farkliliklar göstermektedir. Latsuzbaia A ve ark. (3) 314,868 Pap smear sonucunu değerlendirdikleri çalişmalarında Luxemburg'ta ASCUS oranı'n1 \% 1,27, LSIL oranı'n1 \%1,85, HSIL oranın $1 \% 0,39$ ve toplamda anormal smear sonucu oranın $1 \% 3,8$ olarak tespit etmişlerdir. Gage JC ve ark. (11) New Mexico ve Northern California için ASCUS, LSIL, HSIL oranlarını sirasiyla 4,4-4,04, \%1,8-1,45, \%0,340,21 olarak saptamışlardır. Normal olmayan sitoloji sonucu oranları New Mexico ve Northern California için sırasıyla $\% 7,19$ ve $\% 6,14$ olarak rapor etmişlerdir. 50.436 Pap smear sonucunun değerlendirildiği, Romanya'da yapılan bir çalışmada anormal smear oranı $\% 5,9$, ASCUS $\% \% 2,6$, LSIL $\% 0,8$, HSIL \%0,9 olarak bildirilmiştir (12). Kapila K ve ark. (13) 21 yılı kapsayan bir sürede yapılan Pap smear test sonuçlarını değerlendirdikleri çalışmalarinda Kuvey’te ASCUS \%2,3, LSIL \%0,95, HSIL $\% 0,22$ oranlarında rapor etmişlerdir, anormal smear sonucu oran $1 \% 4,43$ 'tür.

Çalışmamızda smear sonuçlarının yıllara gore dağılımı incelendiğinde 2010 yılında patolojik smear oran1 \%6,6, 2011 y1lında \%5,7 olarak izlenmekteyken 2012 y1linda \%7,2, 2013 y1linda \%11,9 ve 2014 yılında \%9,8 olarak saptanmıştır. Tüm olgular değerlendirildiğinde anormal sonuç oranımız \%8,5 olarak saptanmıştır. Anormal sitoloji sonuçla- r1 2011'den 2014'e doğru belirgin bir artış sergilemektedir.

Ülkemizde yapılan tarama sonuçları incelendiğinde Türkiye Servikal Kanser ve Servikal Sitoloji Çalışma Grubu'nun 2009 yılında yayınladığı, 2007 yılında 33 sağlık merkezinin katılımı ile 140.334 smear sonucunu değerlendirdiği çalışmasinda ASCUS \%1,07, ASC-H \%0,07, LSIL \%0,3, HSIL \%0,17 ve AGC \%0,08 olarak saptanmıştır (14). Attlgan R ve ark. (15) konvansiyonel yöntem ile çalışılan Pap smear sonuçlarını değerlendirdikleri çalışmalarında ASCUS, ASC-H, LSIL, ve HSIL prevalansin 1 sirasiyla $\% 1,9, \% 0,1, \% 0,5, \% 0,1$ ve anormal smear sonucu prevalansinı \%2,8 olarak olarak bildirilmişlerdir. Erdem H ve ark. (16) çalışmalarında konvansiyonel Pap smear sonuçlarını değerlendirmişler, ASCUS, LSIL, HSIL ve AGC oranlarin sirasiyla $\% 2,5, \% 0,3, \% 0,2, \% 0,4$ olarak tespit etmişlerdir. Sengul D ve ark. (17) 32.538 konvansiyonel yöntem ile değerlendirilen Pap smear sonucunu değerlendirmişler ve ASCUS \%1,18, LSIL $\% 0,39$ ve HSIL $\% 0,16$ oranlarında saptamışlardır. $\mathrm{Bu}$ çalışmalarda ASCUS oran1 \%1,07-2,5, LSIL oran $1 \% 0,3-0,5$, HSIL oran $10,6-0,2$ aralığında rapor edilirken bizim çalışmamızda bu değerler sırasıyla $\% 5,25, \% 2,35$ ve $\% 0,4$ olarak tespit edilmiş ve bu sonuçlarla kıyaslandığında anlamlı derecede yüksek olarak saptanmıştır. Çalışmamızda saptadığımız anormal smear sonucu oranımız $\% 8,5$ olup ülkemizde \%1,7-3,4 aralığında bildirilmiș olan orandan yüksektir. Saptadığımız anormal smear oranı Avrupa ülkelerinden yüksek olup Amerika oranlarına yakındır.

Ülkemizde yapılan bir diğer çalışmada 20052009 yı1ları arası Pap smear sonuçları değerlendirilmiş, ASCUS tanısının yıllar içinde anlamlı olarak arttığı, HSIL'in anlamlı oranda azaldı ğı gözlemlenmiştir (18). Ancak bizim çalışmamızda aksi yönde bir sonuç olarak 2010-2014 yılları arasında ASCUS tanıs1 \%5,8'den \%2,2'ye düşerek azalırken LSIL ve HSIL 2010 'da sirasiyla $\% 0,03$ ve $\% 0$ 'dan $\% 5,6$ ve $\% 1,8$ 'e yükselmiştir. Ülkemizde yapılan diğer çalışmalardan farklı olarak saptadığımız sonuçların, çalışmaların değişik yıllarda ve değişik popülasyonlarda yapılması ile ilişkili olduğunu düşünmekteyiz. Ancak, saptadığımız nispeten yüksek LSIL ve HSIL 
oranları, tarama programlarının önemini işaret etmektedir.

Gultekin M ve ark.'nın çalışmasında ülkemizde HPV pozitifliğinin 30-34 yaş arası en sık olduğu ve ilerleyen yaş ile beraber azaldığ 1 saptanmıştır (8). Çalışmamızda LSIL ve HSIL olgularının anlamlı olarak daha genç yaşlarda saptanması $(p<0,001)$ bu sonucu desteklemektedir.

ThinPrep yönteminin "yetersiz materyal" sonucunu azalttığ ve sitopatolojik değişiklikleri daha fazla oranda belirleyebildiği bildirilmiştir (1, 19, 20). Çalışmamızda ThinPrep ile konvansiyonel smear yöntemleri kıyaslandığında ThinPrep' in LSIL saptama oran $1 \% 3,0$ ve HSIL saptama oran 1 $\% 0,5$ idi. Aynı oranlar konvansiyonel yöntemde s1rasıyla $\% 0,2$ ve $\% 0,04$ olarak saptand1. Sonuçlar1miz literatürü destekler niteliktedir.

Sonuç olarak; çalışmamızda ThinPrep yöntemi ile y1llar bazında prekanseröz lezyon saptanma oranlarında bir artış saptadık.

\section{KAYNAKLAR}

1. Tuncer ZS, Başaran M, Sezgin Y, Firat P, Mocan Kuzey $G$. Clinical results of a split sample liquid-based cytology (ThinPrep) study of 4,322 patients in a Turkish institution. Eur J Gynaecol Oncol. 2005;26:646-8.

2. Singh VB, Gupta N, Nijhawan R, Srinivasan R, Suri $V$, Rajwanshi A. Liquid-based cytology versus conventional cytology for evaluation of cervical Pap smears: experience from the first 1000 split samples. Indian J Pathol Microbiol. 2015; $58: 17-21$.

3. Abide CY, Tayyar AT, Karateke A. Hastanemiz Verilerine Göre Anormal Servikal Smear, Preinvaziv Servikal Patoloji ve Servikal Kanser Oranlarının Yillara Göre Değişimi. Zeynep Kamil Tip Bülteni. 2017;48:73-79.

4. Sengul D, Altinay S, Oksuz H, Demirturk H, Korkmazer E. Population-based cervical screening outcomes in Turkey over a period of approximately nine and a half years with emphasis on results for women aged 30-34. Asian Pac J Cancer Prev. 2014;15:2069-74.

5. Erdem H, Şahiner C, Yıldırım Ü, Köse SA, Karataş A, Uzunlar AK, Kadıoğlu N, Şipal S. Servikovajinal Pap Smear Sonuçlarının Klinik Parametrelerle Karşılaştırılması. J Kartal TR 2011;22:121-126.

6. Atilgan R, Celik A, Boztosun A, Ilter E, Yalta T, Ozercan R. Evaluation of cervical cytological abnormalities in Turkish population. Indian J Pathol Microbiol. 2012;55:52-5.

7. Turkish Cervical Cancer And Cervical Cytology Research Group. Prevalence of cervical cytological abnormalities in Turkey. Int J Gynaecol Obstet. 2009; 106:206-9.

8. Kapila K, Sharma PN, George SS, Al-Shaheen A, Al-Juwaiser A, Al-Awadhi R. Trends in Epithelial Cell Abnormalities Observed on Cervical Smears over a 21-Year Period in a Tertiary Care Hospital in Kuwait. Sultan Qaboos Univ Med J. 2015;15:e112-5.
9. Stolnicu S, Musca S, Micu D, Micu L, Moldovan C, Puscasiu L. Prevalence of abnormal Pap smears in a consecutive and previously unscreened population in Romania. Int J Gynaecol Obstet. 2014;124:156-9.

10. Gage JC, Hunt WC, Schiffman M, Katki HA, Cheung LA, Myers O, CuzickJ, Wentzensen N, Kinney W, Castle PE, Wheeler CM; New Mexico HPV Pap Registry Steering Committee. Similar Risk Patterns After Cervical Screening in Two Large U.S. Populations: Implications for Clinical Guidelines. Obstet Gynecol. 2016;128:1248-1257.

11. Wilbur DC, Nayar R. Bethesda 2014: improving on a paradigm shift. Cytopathology. 2015;26:339-42.

12. Karateke A, Gurbuz A, Kabaca C, Zati A, Mengulluoglu $M$, Kir G. Atypical squamous cells: improvement in cytohistological correlation by the 2001 Bethesda System. Eur J Gynaecol Oncol. 2004;25:615-8.

13. Gultekin M, Zayifoglu Karaca M, Kucukyildiz I, Dundar S, Boztas G. Semra Turan H, Hacikamiloglu E, Murtuza $K$, Keskinkilic B, Sencan I. Initial results of population based cervical cancer screening program using HPV testing in one million Turkish women. Int J Cancer. 2018;142:1952-1958.

14. Nayar R, Wilbur DC. The Bethesda System for Reporting Cervical Cytology: A Historical Perspective. Acta Cytol. 2017;61:359-372.

15. Upendram P, Sahni S, Mohiuddin K, Poornima $S$, Gourishankar B, Kumar Vattam K, Boddala P, Jayashankar E, Mohiuddin S, Kamineni V, Mohan V, Houldsworth $J$, Hasan Q. Amplification of specific chromosomal regions assessed by fluorescent in situ hybridization on Pap smears to be added as screening tool for identifying women at risk of progressing to cervical cancer. Tumour Biol. 2017;39:1010428317698363.

16. Arbyn M, Roelens J, Simoens C, Buntinx F, Paraskevaidis E, Martin-Hirsch PP, Prendiville WJ. Human papillomavirus testing versus repeat cytology for triage of minor cytological cervical lesions. Cochrane Database Syst Rev. 2013;(3):CD008054.

17. Singhakum N, Laiwejpithaya S, Chaopotong P. Digital Cervicography by Simply Portable Device as an Alternative Test for Cervical Cancer Screening in Rural Area of Thailand. Asian Pac J Cancer Prev. 2018;19:1145-1149.

18. Latsuzbaia A, Hebette G, Fischer M, Arbyn M, Weyers $S$, Vielh P, Schmitt F, Mossong J. Introduction of liquid-based cytology and human papillomavirus testing in cervical cancer screening in Luxembourg. Diagn Cytopathol. 2017;45:384390.

19. Elfström KM, Arnheim-Dahlström L, von Karsa L, Dillner J. Cervical cancer screening in Europe: Quality assurance and organisation of programmes. Eur J Cancer. 2015;51:95068 .

20. Costa MO, Heráclio SA, Coelho AV, Acioly VL, Souza PR, Correia MT. Comparison of conventional Papanicolaou cytology samples with liquid-based cervical cytology samples from women in Pernambuco, Brazil. Braz J Med Biol Res. 2015;48:831-8. 